\title{
The Review of the Development of Homosexuality in Chinese Cities
}

\author{
Xinnan Zhao ${ }^{1 *}$ \\ ${ }^{1}$ The Affiliated High School of Peking University Beijing 100083 \\ ${ }^{*}$ Corresponding author.Email: zhaoxinnan@i.pkuschool.edu.cn
}

\begin{abstract}
The problem of homosexuality remains an important challenge in Chinese urban society. This paper aims to reviews the social conditions of homosexuality in Chinese urban areas in recent years by highlighting the background of homosexuality in Chinese society and the education system. Though previous articles have fully discovered the inequity of homosexuals and many of them have given out suggestions, the change of public and governmental attitude is little. The main findings of this paper are: 1) low social acceptance of homosexuality; 2) discriminations of homosexuality in the labour market; 3) homosexuality has little public identified city space; 4) bullying behaviours exist towards homosexuality; 5) stigmatization is an important issue to be considered. This paper mainly presents a comprehensive review from social and educational perspectives in the Chinese urban area and propounds possible solutions based on the primary causes.
\end{abstract}

Keywords: Homosexuality, City, Society, Education, China.

\section{INTRODUCTION}

Recent theoretical developments on homosexuality in Chinese urban society have revealed that the homosexual community faces discrimination and prejudice in China. The main problem is that the Chinese public does not acknowledge the presence of homosexuality. In the APA (American Psychological Association) dictionary of psychology, sexuality is defined as follows: all aspects of sexual behaviour, including gender identity, orientation, attitudes, and activity [1]. This review only focuses on homosexuality -- which is referred to as same-sex sexual orientation [2]. Recent researchers in the perspective of ethics or egalitarianism mostly believe that homosexuality should be accepted in every aspect. However, to our knowledge, the negative attitudes of homosexuality have little change in Chinese society in many years. To clarify the influence and the importance of the problem, the researcher of this review characterizes different aspects of the inequity of homosexuality separately from social and educational perspectives. This work aims to promote equality regardless of sexual orientation. This review accelerates the normalization of homosexuality in China by bringing this minority to public concerns.

\section{BACKGROUND OF HOMOSEXUALITY IN CHINESE SOCIETY}

\subsection{Social Acceptance}

Although CCMD-3 (Chinese Classification of Mental Disorders 3rd edition) has clearly stipulated that homosexuality is not a kind of mental-disease as early as 2001, urban Chinese now still hold the opinion that homosexuality is abnormal. According to Wei, homosexuals are facing serious social discrimination and prejudice, and they are stigmatized greatly [1]. In Wang's article, he states that Chinese homosexuals' communities easily receive special treatment from others [2]. The mainstream attitudes which give out from the heterosexual perspectives do not accept this minor community. In this case, the so-called "normal people" refers in particular to heterosexuals, separate themselves from homosexuals unconsciously and repel and isolate them. However, according to a survey of another research, the statistic results show that about $72 \%$ of the subjects agree that homosexuals should have equal rights with heterosexuals. But when the situation comes close -- if the person has a homosexual child, neighbour, employee, etc. -- only $40 \%$ of people report that they can well-accept homosexual people. The researcher of this survey Yan, argues in her paper that "These results reflect that the so- 
called acceptance of the homosexuals in Chinese social environment nowadays is a fake acceptance" [3]. The actual level of acceptance may be even lower due to the response bias. These results point out that Chinese urban society does not accept homosexuals mainly.

\subsection{The Environment of Employment}

The society is mostly unwelcomed for homosexuals, especially for the aspect of employment. Quantitative results revealed that the reversion rate the homosexual males received is $7 \%$ less than heterosexual males in the labour-market based on the data from Shanghai and Shenzhen City in China [4]. Discrimination exists not only on the part of looking for jobs but also influences the treatments of homosexuals even if they receive a job offer and start working with difficulty. In 2015, a homosexual male named $\mathrm{Mu} \mathrm{Yi}$ took his company to court for the company dismissed him after being exposed to being a homosexual. He was famous as one of the "red cap" litigants in a short video in which they admitted that they are homosexuals [5]. Then Mu Yi's company dismissed him because the manager thought that his character in this video would prejudice the company. These data and this example together show that homosexuality is not preferred in the labor market, and homosexuals are likely to be repelled and discriminated against in the work environment. Specifically, the rejection rate of homosexuals is larger than heterosexuals in the same condition.

\subsection{City Space}

From the low social acceptance of themselves, homosexuals know that their living space in a city is doomed to be little. But they have their scattering space secretly. Homosexuality is always related to special public spaces reflected in specific locations in a city, although these locations' names differ greatly in different cities [6]. For example, Li finds out that in Hongkong, the space for homosexuals is called "Yuchang", but Fu discovers that in Chengdu, the name has changed to "Piaochang" [7, 8]. Moreover, there is a general name, "Dianer" which can be used in every city in the Chinese Mainland for parks, shower rooms, and bars where homosexuals gathered. In these special places, homosexuals use their specific expressions, gestures, argots, and gender performances to show themselves as coteries to find their companions [6]. All these actions are half hidden due to the severe circumstance of homosexuality in Chinese society.

\section{BACKGROUND OF HOMOSEXUALITY IN THE CHINESE EDUCATION SYSTEM}

\subsection{School Bullying}

School bullying happens commonly in and out of campus, and it is greatly harmful to teenagers' physical and psychological health [9]. Without exception, research shows that the mental-health of sexual minority students is also related to their experiences of school bullying [10]. According to Liu's research in high school students, students with homosexual tendencies are more likely to experience bullying than others. Specifically, the possibility of students with homosexual orientation experience physical bullying is much stronger than heterosexuals, bisexuals, and uncertain sexual orientation students [11]. In a news report in 2021, a 16-year-old boy who studied in a vocational school in Beijing experienced serious school bullying because of the identity of homosexual and got depressive disorder. The bullying includes ripping down his clothes, taking nude photos during his sleep, posting the photos on WeChat (the most popular instant-communicate application in China) group, sexual harassment, mental abusing and sneering, etc. However, the teacher's punishment gives to the 8 bullies is a written self-criticism, and the school manager prefers to reconcile the parties concerned [12]. The characteristics of acquaintance society in a school, for example, forming cliques, push the discrimination forward and has a great influence on homosexual teenagers. Also, the growth environment of Chinese urban teenagers is infertile due to the attitudes of teachers, school managers, parents, and judiciary authorities.

On the other hand, Liu's research points out that students with homosexual tendencies are more likely to implement school bullying, including verbal, physical, and relational bullying behaviours, than heterosexual and other sexual minorities students [11]. Liu argues that this is because the relatively complex personality and insecurity of homosexuals make them use the behaviours of attack and bully as protections to protect themselves [11]. A vicious circle appears as homosexual students are more likely to be bullied, and due to this insecurity, they are more likely to bully others.

\subsection{Stigmatization in Universities' Textbooks and Courses}

In 2001, CCMD-3 eliminated homosexuality as one of the gender identity disorders. However, according to Liu, the new definition of homosexuality does not clearly reduce the prejudice in society towards homosexuals [13]. Though undergraduate students are regarded as a community of high-intellectual level, their attitudes towards homosexual diverse from each other [14]. Many textbooks and brochures published by universities' publishing houses that are used in mental health courses 
for college students still define homosexuality as a kind of mental disorder [15]. A lesbian teenage girl Xixi brought a lawsuit against Jinan University Press for the book Mental Health Education of Undergraduates it published in 2013 described being gay as a mental disorder [16]. In an interview of homosexuality in the textbook, the interviewees mainly report 3 kinds of books used in undergraduate education, including Medical Psychology, Psychiatry, and Abnormal Psychology. [15]. Some interviewees reported that the Psychiatry textbook they read defines homosexuality as a mental disorder. It is visible that homosexuality is only vindicated in the academic field, but the education system still creates a stigma on it. This stigmatization of homosexuals results in severe discrimination and prejudice in public and makes homosexuals live difficultly. Education is working as the most important influence factor on shaping one's character. Therefore, the stigmatization of homosexuals needs to be corrected instantly otherwise homosexuality would never be vindicated.

Compared with textbooks, teachers' attitudes as immediate causes play a more important role in shaping the notion of homosexuality among students. But because teachers are elders that their thoughts are more likely to be traditional, their attitudes toward homosexuality are mostly negative. In her paper, Wang states that in the mental health courses for undergraduates, romantic relationship between the same sex is ignored by teachers deliberately, and teachers themselves are lack of knowledge about homosexuality. Teachers may use the description in this way: Except for our normal romantic relationships, homosexuality also exists; Homosexuality belongs to the third sex [17]. Although this kind of description does not directly state that homosexuality is abnormal, the teachers' negative attitudes to their undergraduate students are obvious.

\section{HOMOSEXUAL-RELATED PROBLEMS IN THE SOCIETY AND THE EDUCATION SYSTEM}

\subsection{The Causes of Homosexual-related Problems in Chinese Publics}

The low acceptance of homosexuality in Chinese society results in discrimination and prejudice towards homosexuals. This inequity is embodied in many aspects and seriously influence the lives of homosexual in Chinese urban areas. The unfair job opportunity offers to homosexuals, the lack of activity space, and other problems that have been illustrated in the previous paragraphs are different consequences of low public acceptance. Here are two possible reasons to explain why Chinese people cannot accept homosexuality easily.

\subsubsection{Cultural Effects}

Different from Western individualistic heroism, Chinese traditional culture highly esteems collectivism and emphasizes the importance of "home." From the lunar festival, for example, the Lantern Festival, the Chinese New Year, the Mid-Autumn Festival, etc. Ancient Chinese express their cultural value as "reunion" and "solidarity". However, this culture value destined that exclusiveness is obvious in the collective. Clearly, homosexuality as a new-born minority in Chinese society is hard to be accepted by the majority -- heterosexual collective. Thus, the way of accepting homosexuality for Chinese people is doomed to be rough and long. The attitude of the majority should have time to be gradually permeated through people step by step.

On the other hand, cultural effects also play a role in homosexuals. Statistic results show that homosexuals are more likely to have suicidality than heterosexuals [1]. The willingness to suicide partly derives from a selfcontradictory mind. Influenced by the traditional culture, Chinese people take continuity of ethnicity as the most important part of life. The Chinese proverb - "There are three forms of unfilial conduct of which the worst is to have no descendants" - is interiorized in most people's minds [2]. But for homosexuals, homosexual behaviours cannot result in parturition biologically, which means impiety in Chinese traditional culture. Since Chinese people attach importance to filial piety, homosexuals struggle with their self-consciousness and cultural-based value, and this partly explains why homosexuals are the high-risk group of psychological illness.

\subsubsection{Incomprehension}

The public knowledge of homosexuality in Chinese society is little. For the elders who break away from the education system, there are few ways to get to know homosexuality. The little news about homosexuals is the only possibility for the public to get an approach to homosexuality. However, the unsupportive attitudes of the Chinese government lead to the erasures of this news. Because of the lack of information on homosexuality in the Chinese elder population, society lacks rational public discussion on this topic. In fact, the incomprehension and the lack of communication with the homosexual community generate stereotypes among the public, which caused prejudice in society [20].

In the case of students, who are still attached to the educational system, the official channel they gain information is from teachers and textbooks. However, neither of these two ways gives appropriate knowledge of homosexuality to young people. Previous paragraphs have mentioned that teachers, as part of the elderly population, are more traditional and unfamiliar to homosexuals themselves. And textbooks, as publications that education commissions have commanded, are 
influenced more by government attitudes than academic positions in Chinese cases.

The outcome is Chinese people know little about homosexuality, and this results in unavoidable prejudice and discrimination.

\subsection{Suggestions Based on the Problems and the Causes}

Overviewing the consequences and the causes of low public acceptance that demonstrate in previous paragraphs and combining other academic works, the researcher of this review arises several suggestions for the target population of this paper in terms of the difficult situation. To ease the current main problem of homosexuals -- they are unacceptable in the Chinese publics - the change should take part in both public and homosexual perspectives

\subsubsection{Suggestions in the Perspective of Publics}

Since discrimination, bullying, and other harmful conditions are serious consequences of prejudice and denial, the Chinese public should get enough information and communication with the homosexual community to eliminate their stereotypes and prejudice. Explicitly, this refers to publicise correct and specific information about homosexuals to the public and advocate for the respect that homosexuals deserved.

For government sectors, NGOs (Non-Governmental Organizations), and other capable individuals or groups, the feasible method is to publicise the actual information and social environment of homosexuals by holding information sessions, cultivating teachers and speakers for sessions, produced and hung out official brochures, etc. In addition, the researcher of this review holds the view that these organizations should actively carry out further studies using investigation, survey, interview, or experiment methods to reveal the current situation and living conditions of homosexuals in Chinese urban society to arise public empathy.

For the Chinese public, they should get the awareness to reflect on their consciousness about homosexuals. Thus, social media and the government sector should duly extend the limitation on homosexual news and other forms of content on the internet.

\subsubsection{Suggestions in the Perspective of Homosexual Community}

The goal of suggestions in the perspective of the homosexual community is to better protect homosexual individuals based on the fact that they are the high-risk population of suicide. The protection should cover the following aspects: 1) formal LGBT friendly psychological intervention departments in and out of the campus; 2) harsher regulator on bullying behaviour in campus and enterprise; 3) establish homosexual or LGBT mutual-help group in and out of campus.

The first aspect relies on professionals and location. Schools, organizations, or individuals who are willing to build up formal psychological intervention departments should actively seek psychiatrists or sexologists who fully accept homosexuality to join in the program. In addition, to protect the clients' privacy, the department's location may be better to be undisturbed, and the sound insulation effect of rooms needs to be good. This method is for homosexual individuals who recognized themselves as people in need.

The second aspect is the most direct way to protect the physical and mental health of homosexuals. Though homosexuality is absent in Chinese legislation, the supervisors can formulate regulations based on the legislation of human rights combined with school spirit or enterprise culture.

The third aspect is mainly held by students themselves on campus or NGOs in society. The mutualhelp groups can gather people of the same identity together in a space full of a sense of security since the participants have strong empathy for each other.

In addition, in the position of homosexuals, they should be encouraged to find help by going to formal departments, attending mutual-help groups, calling the emergency hotline when they feel they need any support. These suggestions are for decreasing suicidal behaviours in the homosexual communities and providing a safer environment for them.

\section{CONCLUSION}

In summary, this paper reviews the situation of homosexuality in Chinese urban society. The researcher of this review respectively expounds 5 problems that homosexuals in China are facing as follows in social and educational perspectives: 1) low social acceptance; 2) discrimination in the labour market; 3) little public identified city space; 4) bullying behaviours; 5) stigmatization. In the last part, this review analyses possible causes and solutions in the paratactic two parts. The target population of this review is teachers, school managers, members of education commissions, and related NGOs. This paper raises the awareness of these populations of homosexuals and inspires them to develop more implemental solutions based on the primary causes of homosexuality in future studies.

\section{REFERENCES}

[1] APA Dictionary of Psychology. (2020). Retrieved April 25, 2021, from https://dictionary.apa.org/homosexuality 
[2] APA Dictionary of Psychology. (2020b). Retrieved April 25, 2021, from

https://dictionary.apa.org/sexuality

[3] Wei, L. (2012). Study on Psychological Health Status and Behaviour Characteristics of Lesbians in Shandong Province (Unpublished master's thesis). Shandong University, Jinan, Shandong, China.

[4] Wang, Z.G. (2019). Ethical thoughts on the phenomenon of homosexuality in contemporary society. Jiangxi Social Science, 39(395), 231-237. http://jxsh.cbpt.cnki.net/WKE/WebPublication/pap erDigest.aspx?paperID=2277adbd-5af6-4f7b-9bfdeab2137c68c5

[5] Yan, M.J. (2021). Study on the factors of suicidal ideation in homosexuals in China. Journal of Western, 131, 61-64.

https://doi.org/10.16721/j.cnki.cn61$1487 / \mathrm{c} .2021 .02 .019$

[6] Wang, F., \& Huang, P.X. (2019). Homosexual discrimination in the recruitment market: Experimental evidence from randomised emails. World Economic Papers, 01(05), 74-89. http://sjjjwh.magtech.com.cn/CN/Y2019/V01/I05/7 4

[7] Guangzhou Daily. (2015, November 26). The first case of workplace discrimination based on sexual orientation in China was pronounced in the final trial, and one of the "little red caps" lost the lawsuit. Guancha.

https://www.guancha.cn/society/2015_11_26_3427 19.shtml

[8] Wei, W., \& Fu, X.X. (2013). City, space and homosexuality: China's local experience and regional differences. Youth Studies, 01, 68-76. https://kns.cnki.net/kcms/detail/detail.aspx?dbcode $=$ CJFD\&dbname $=$ CJFDLAST2016\&filename $=Q N$ YJ201301009\&v $=\mathrm{m} 4$ tRy8ifAJONhP2xe\%25mmd 2B79uATdwAeszocUaqbPyt86\%25mmd2BZ080g PpR3OmvcxJKB81QfXA

[9] Li, Y.H. (1998). Homosexual subculture. China Today Press.

[10] Wei, W. (2007). "Piaopiao" in the city: the emergence and change of homosexual identities in local Chengdu. Chinese Journal of Sociology, 27(01), 67-97. https://doi.org/10.15992/j.cnki.311123/c.2007.01.004

[11] Wu, R.P., Lu, C.Y, \& Li, P.S. (2018). Prevalence and relative factors of school bullying behaviours among high school students in Shanxi province. Chinese Journal of Public Health, 34(3), 313-317. https://doi.org/10.11847/zgggws1113594
[12] Wei, C.Z., \& Liu, W.L. (2015). The association between school bullying and mental health of sexual minority students. Chinese Journal of Clinical Psychology, 23(4), 701-705. https://doi.org/10.16128/j.cnki.10053611.2015 .04 .030

[13] Liu, X.Q., Peng, C., Huang, Y.X., Yang, M.S., Wen, L.H., Qiu, X.Y., \& Wang., Z. (2020). Association between sexual orientation and school bullying behaviours among senior high school students. Chinese Journal of Public Health, 36(6), 880-883. https://doi.org/10.11847/zgggws1122177

[14] Red Star News. (2021, March 16). A 16-year-old boy in Beijing was bullied and harassed on campus: They filmed me on the top bunk and posted it in the group [Video file]. Retrieved from https://video.sina.cn/news/2021-03-16/detailikkntiam2622255.d.html? cmntg=0\&node_id $=3776$ $6 \& \mathrm{cmntg}=0$.

[15] Liu, Y., Zhang, L.H., Shen., Q., Cai, Y., \& Liu H.Q. (2017). Awareness and attitudes towards gender/sexual minority among psychiatrists and psychologists. Chinese Journal of Human Sexuality, 26(1), 133-139. https://doi.org/10.3969/j.issn.16721993.2017.01.044

[16] Fang, G. (Ed.). (2012). Gender diversity: Theoretical and practical research. Taipei, Taiwan: Wan You Press.

[17] Gay and Lesbian Campus Association of China. (2014, August). Investigation report on the error and stigmatization of homosexuality in Chinese college textbooks and its influence. Author. Retrieved from http://www.glcac.org.cn

[18] Wee, S. (2020, October 28). China's stance on homosexuality has Changed. Its textbooks haven't. Retrieved April 21, 2021, from https://www.nytimes.com/2020/10/28/business/inte rnational/china-gay-homosexuality-textbookslawsuit.html

[19] Wang, W.Y. (2013). Homosexuality content in college mental health course. Chinese Journal of Human Sexuality, 22(8), 86-91. https://doi.org/10.3969/j.issn.16721993.2013.08.026

[20] Yan, X. (2016). Analysis of the approach to equal protection of rights of homosexuals. Journal of Southeast University(Philosophy and Social Science), 18(Supplement), 124-127. https://doi.org/10.13916/j.cnki.issn1671511x.2016.s2.038 